\title{
Study on comprehensive utilization technology of low concentration coal bed methane
}

\author{
$\mathrm{Lu} \mathrm{XIAO}{ }^{1,2^{*}}$ \\ ${ }^{1}$ Chongqing Research Institute of China Coal Technology \& Engineering Group Corporation, No.55, Shangqiao village, Shapingba \\ District, Chongqing, China. \\ ${ }^{2}$ National Key Laboratory of Gas Disaster Detecting Preventing and Emergency Controlling, No.55, Shangqiao village, Shapingba \\ District, Chongqing, China.
}

\begin{abstract}
Aiming at the problems of low utilization rate and serious environmental pollution caused by low concentration coal bed methane emission in a coal mine, the utilization technology of low concentration coal bed methane was studied by means of field investigation and theoretical calculation, and the technical solution of comprehensive utilization of low concentration coal bed methane combining regenerative oxidation and cryogenic liquefaction was obtained, which realized the "coal and gas are co-mined and shared" and constructed the virtuous cycle development of " use to promote pumping, pumping to promote safety". The research shows that: the low concentration coal bed methane with concentration of about $5 \%$ is converted into high temperature flue gas by regenerative oxidation, and the heat energy is extracted to realize the heating in the mining area; the coal bed methane with concentration of more than $35 \%$ is purified and liquefied into LNG product by cryogenic liquefaction, so as to realize long-distance transportation. The technology improves the utilization rate of coal bed methane in the mining area and eliminates the burning of coal for heating. The annual utilization of pure gas is 53.38 million $\mathrm{m}^{3}$, generating economic benefits of 211 million yuan and reducing $\mathrm{CO}_{2}$ equivalent by $767,000 \mathrm{t}$. The safety, economic and environmental benefits are remarkable. This technology has practical significance to improve the utilization rate of gas and promote the realization of the goal of zero gas emission.
\end{abstract}

\section{Introduction}

With the vigorous development of industrial technology and the rapid increase of resource consumption [1], the situation of air pollution is grim, regional atmospheric environment problems are becoming increasingly prominent, and the pressure of pollution prevention and control is increasing, which damages people's health and affects social harmony and stability [2]. Environmental protection is one of the important supports for sustainable development. The main component of coal bed methane (i.e. coal mine gas) is methane [3]. Methane is a kind of greenhouse gas, which will produce greenhouse effect when discharged into the atmosphere [4]. The greenhouse effect produced by direct emission of methane is 20 30 times of that of carbon dioxide, which causes great environmental pollution [5]. In addition, coal mine gas has been a major hidden danger affecting the safety of coal mining [6].

Coal bed methane mainly comes from underground gas drainage, and the drainage pipe network is in a negative pressure state [7]. A large amount of air infiltrates into the pipe network, resulting in the low concentration of coal bed methane [8], which is not convenient to use and directly discharged [9]. The United Nations
Framework Convention on Climate Change and the Kyoto Protocol require the world to control and reduce greenhouse gas emissions. Coal mine gas is fully burned and has little pollution. If it is used, the harm can be changed into treasure. It not only saves energy, but also reduces the air pollution, so as to achieve the purpose of environmental protection. The coal bed methane with concentration more than $35 \%$ is purified and liquefied into LNG product by means of deep cold liquefaction, so as to realize long-distance transportation.

In this context, combined with the technology of coal and gas co-mining and sharing [10-12] and according to the actual energy demand of coal mines, the emission of low-concentration coal bed methane can be reduced by utilizing the technology of comprehensive utilization of low-concentration coal bed methane. The coal bed methane with a concentration of about $5 \%$ is converted into high temperature flue gas by means of regenerative oxidation, and the heat energy is extracted from it [13], which can realize the heating in the mining area, thus replacing the coal-fired boiler. The coal bed methane with concentration more than $35 \%$ is purified and liquefied into LNG product by cryogenic liquefaction method, so as to realize long-distance transportation. Aiming at the problem of low utilization rate of low concentration coal

*E-mail: xiaolu8317@126.com 
bed methane in coal mine, this paper analyzes and studies the comprehensive utilization technology of low concentration coal bed methane by means of field investigation and theoretical calculation in the background of coal bed methane utilization and energy utilization in this coal mine, which has a guiding significance for other coal mines to realize low concentration coal bed methane emission reduction.

\section{Investigation of gas source in coal mine}

A coal mine can produce 5 million tons of coal every year, which belongs to the coal and gas outburst mine, and there is a large amount of coal seam gas in the coal seam. According to the report of field supplement survey and the measurement data of coal seam gas parameters, the total CBM reserves of the coal mine are 24.36 billion $\mathrm{m}^{3}$, of which the recoverable coal seam reserves are 12.9 billion $\mathrm{m}^{3}$, the reserves of the non-recoverable adjacent coal seams within the mining impact range of the recoverable coal seam are 7.4 billion $\mathrm{m}^{3}$, and the surrounding rock reserves are 4.06 billion $\mathrm{m}^{3}$.

Coal mine as the central air shaft square pumping station adopts the comprehensive gas drainage method of this coal seam, adjacent strata and goaf drainage, and the high and low negative pressure drainage systems are independent. A total of 10 gas drainage pumps are installed in the pump station, 5 for use and 5 for standby. The drainage system of this coal seam is equipped with 6 sets of water ring vacuum pumps with a total extraction capacity of $2040 \mathrm{~m}^{3} / \mathrm{min}$ (excluding standby); the drainage system of adjacent strata is equipped with 4 sets of vacuum pumps with a total extraction capacity of $1248.6 \mathrm{~m}^{3} / \mathrm{min}$ (excluding standby).

According to the information provided by the coal mine ventilation department, in 2018, the low concentration coal bed methane extracted from the coal seam in the mine was 27.24 million $\mathrm{m}^{3}$, with a concentration of about $5 \%$, which was completely drained. The coal bed methane extracted from adjacent strata is 61.46 million $\mathrm{m}^{3}$, the concentration is more than $35 \%$, and the utilization is 20.77 million $\mathrm{m}^{3}$. It is mainly used for heating in mining area, bathing, central air shaft heating, coal bed methane driven air conditioning unit, coal bed methane power generation, slime drying, canteen gas, and gas for nearby residents, etc. The remaining 40.69 million $\mathrm{m}^{3}$ is not used, all of which are discharged, resulting in the waste of high-quality clean fuel in coal mine.

At present, the utilization of gas in the mining area is mainly high concentration gas, the utilization of low concentration gas is 12.5 million $\mathrm{m}^{3} / \mathrm{a}$ (converted into pure gas), and the surplus is 27.5 million $\mathrm{m}^{3} / \mathrm{a}$ (converted into pure gas), with the utilization rate of about $37.5 \%$. In addition, the high concentration gas allowance fluctuates greatly with seasons. The allowance in non-heating season is $91200 \mathrm{~m}^{3} / \mathrm{d}$ (pure), and that in high load period in heating season is only $19200 \mathrm{~m}^{3} / \mathrm{d}$ (pure).

In addition, there are a lot of low concentration gas emptying and waste heat of power plant flue gas unused in the mining area, which is a serious waste. If the waste heat of low concentration gas and gas power plant flue gas is utilized, it can be used for slime drying, central wind wells wellbore heating, bathing and heating in living area.

In order to solve the problems existing in gas utilization, it is proposed to optimize the whole gas utilization system, use the remaining low concentration gas and waste heat of power plant to replace part of high concentration gas, and utilize the high concentration gas by cryogenic liquefaction way, so as to improve the utilization rate of gas and maximize the benefit.

\section{Comprehensive utilization scheme of coal bed methane}

The selection of comprehensive utilization scheme of coal bed methane should follow the principle of "zero emission of gas drainage, comprehensive utilization of heat energy and maximum benefit". According to the concentration and volume of coal bed methane drainage, the location of pumping station and the utilization location, utilization mode and concentration of downstream products, as well as the matching relationship of utilization with seasonal changes, the current situation and expected demand of energy in the mining area should be comprehensively considered to optimize the energy supply mode and the utilization scheme of coal bed methane.

As mentioned above, 27.24 million $\mathrm{m}^{3}$ of low concentration coal bed methane with a concentration of about $5 \%$ is discharged every year. This part of coal bed methane can generate heat energy by regenerative oxidation. One part of the heat energy can be used for coal slime drying in the mining area to replace the hot air stove for coal slime drying, and the other part can replace the coal-fired boiler in the production area to produce hightemperature flue gas and heat the air into the shaft to guarantee the working face is free of ice in the winter, the surplus heat energy can provide steam or hot water for the mining area. Steam can be used for power generation, and hot water can be used for bathing and laundry. According to the heat consumption scale of the mining area and the gas supply capacity of low concentration coal bed methane, it is suggested to build a low concentration coal bed methane regenerative oxidation device with a feed gas treatment capacity of $200000 \mathrm{~m}^{3} / \mathrm{h}$, and the designed treatment capacity of methane concentration is $1.2 \%$. Considering the oxidation efficiency and heat transfer efficiency of the device, the total heat output is $17745 \mathrm{~kW}$, the low concentration coal bed methane consumption is $38.6 \mathrm{~m}^{3} / \mathrm{min}$, and the operation scale of the device is $193000 \mathrm{~m}^{3} / \mathrm{h}$. In the process of heat transfer, the heat efficiency of high-temperature flue gas heat exchanger and waste heat boiler is $85 \%$, so the heat provided by hightemperature flue gas heat exchanger and waste heat boiler is $15083 \mathrm{~kW}$, which can fully meet the heat load demand of slime drying after being transported to the heating end through the pipeline network along the way, and the remaining unused heat can replace part of the heat load of gas steam boiler.

For the 40.69 million $\mathrm{m}^{3}$ of unused and drained CBM, the concentration of which is more than $35 \%$, the method of cryogenic liquefaction can be used to extract the 
methane in low-concentration CBM, and then the methane can be purified and liquefied into LNG product. According to the supply and concentration of CBM, a set of cryogenic liquefaction device with processing scale (mixing capacity) of $300000 \mathrm{~m}^{3} / \mathrm{d}$ of feed gas can be built, and the concentration of CBM can be designed as $35 \%$. It has been calculated that the device can produce 25,333 t of LNG product per year.

Both the regenerative oxidation device and the cryogenic liquefaction and extraction LNG device can operate throughout the year with high utilization rate. Except for the maintenance period of the device, zero emission of coal mine gas resources has been basically realized, and considerable subsidy income of coal bed methane utilization can be obtained. In addition, since the heating season is the peak of LNG price, when the gas quantity in the heating season is insufficient, the gas supply of other utilization methods can be adjusted appropriately to ensure the operating load of the liquefaction plant as far as possible and improve economic benefits.

\section{Cryogenic liquefaction}

\subsection{Technological process.}

The process of extracting methane from low concentration coal bed methane by cryogenic liquefaction mainly includes: feed gas metering and compression, acid gas removal, dehydration and drying, coal bed methane liquefaction and distillation separation, LNG storage and loading, bog treatment and LNG gasification system. Figure 1 is the process flow chart of the device. In the process design, the explosion characteristics of the pressurization process should be theoretically calculated and experimentally demonstrated according to the specific mole fraction of methane and other combustible impurities in the feed gas, and the appropriate operating pressure, operating temperature and fluid flow rate should be selected to ensure that the methane concentration in the pressurization process of coal bed methane is in the safe area beyond the explosion limit.

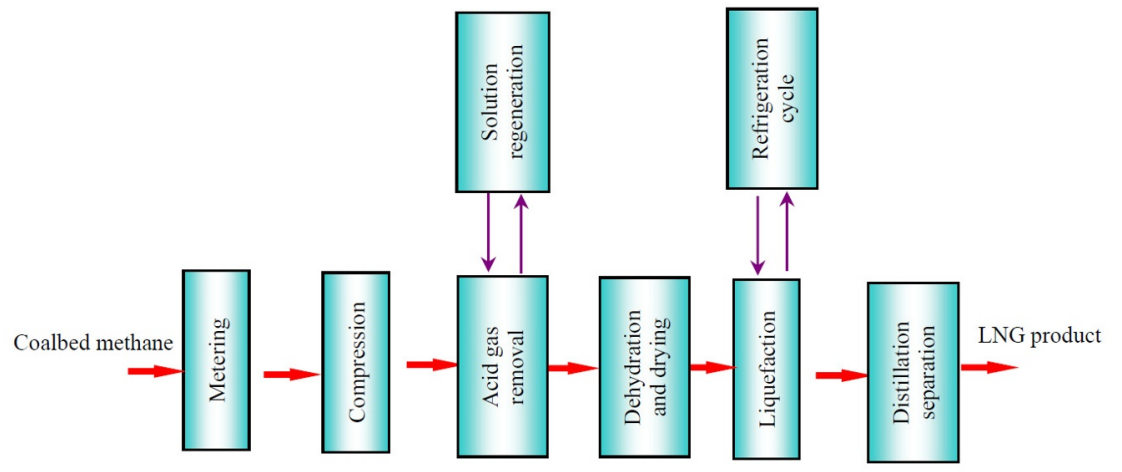

Figure 1. Cryogenic liquefaction process diagram of low concentration coal bed methane

There are two channels in the liquefied cold box, which are coal bed methane channel and refrigerant channel respectively. The liquefaction cold box is mainly composed of plate fin heat exchanger group and distillation column. The plate fin heat exchanger group mainly plays the role of precooling before separation of coal bed methane. The distillation column provides a place for liquefaction and purification of coal bed methane. LNG product mainly flow out after gathering at the bottom of the column. The cooling capacity required for liquefaction and separation is provided by the mixed refrigerant cycle, which is powered by the mixed refrigerant compressor.

After acid gas removal and dehydration, the feed gas can be regarded as a mixture of $\mathrm{CH}_{4}, \mathrm{O}_{2}, \mathrm{~N}_{2}$ and other components. The molar fraction of $\mathrm{CH}_{4}$ is $35 \%$. The mole fraction of is $13 \%$; the mole fraction of $\mathrm{N}_{2}$ is $52 \%$. Feed gas flow rate $F=300$ thousand $\mathrm{m}^{3} / \mathrm{d}=12500 \mathrm{~m}^{3} / \mathrm{h}$. According to the separation task, the purity of LNG product at the bottom of the distillation column is required to be $\geqslant 99.5 \% ; \mathrm{O}_{2}$ content $\leqslant 0.5 \%, \mathrm{CH}_{4}$ recovery $\geqslant$ $98.5 \%$.

\subsection{Material balance}

According to the material balance before and after the separation of CBM, the methane recovery rate is calculated as follows:

$$
\eta=\frac{W \times \varphi_{W}}{F \times \varphi_{F}}
$$

Where, $\eta$ is the recovery rate of methane in $\mathrm{LNG}$ product; $W$ is LNG production, $\mathrm{m}^{3} / \mathrm{h} ; \varphi_{W}$ is the purity of LNG, that is, the mole fraction of methane in the LNG product at the bottom of the tower; $F$ is the feed gas flow $\mathrm{m}^{3} / \mathrm{h} ; \varphi_{F}$ is methane content (mole fraction) of feed gas.

Substituting $F=12500 \mathrm{~m}^{3} / \mathrm{h}, \varphi_{F}=0.35, \varphi_{W}=0.995$, $\eta=0.985$, it can be calculated that the gas production at the bottom of the tower is $W=4331 \mathrm{~m}^{3} / \mathrm{h}$; the nitrogen and oxygen tail gas flow at the top of the tower is $D=F-W=8169 \mathrm{~m}^{3} / \mathrm{h}$; the nitrogen and oxygen tail gas flow at the top of the tower is $\varphi_{D}=\frac{F \times 0.35 \times(1-0.985)}{D}=0.803 \% \quad$; the nitrogen content at the top of the tower is $\varphi_{D, N}=\frac{F \times 0.52}{D}=79.57 \%$; the oxygen content at the top of the tower is $\varphi_{D, O}=1-0.803 \%-79.57 \%=19.63 \%$. Table 1 shows the material balance data of CBM channel. 
Table 1. Material balance of coal bed methane in liquefied cold box

\begin{tabular}{|c|c|c|c|c|}
\hline \multirow{2}{*}{ Gas name } & \multirow{2}{*}{$\begin{array}{c}\text { rate of } \\
\text { flow } \\
\left(\mathrm{m}^{3} / \mathrm{h}\right)\end{array}$} & \multicolumn{3}{|c|}{ mole fraction } \\
\cline { 3 - 5 } & & $\mathrm{CH}_{4}$ & $\mathrm{O}_{2}$ & $\mathrm{~N}_{2}$ \\
\hline feed gas & 12500 & 0.35 & 0.13 & 0.52 \\
\hline $\begin{array}{c}\text { tail gas at the } \\
\text { top of the tower }\end{array}$ & 8169 & 0.00803 & 0.1963 & 0.7957 \\
\hline $\begin{array}{c}\text { product at the } \\
\text { bottom of the } \\
\text { tower }\end{array}$ & 4331 & 0.995 & 0.005 & 0 \\
\hline
\end{tabular}

\subsection{Cooling capacity calculation}

According to the energy balance calculation, the cooling capacity of the oxygenated coal bed methane liquefaction cold box is shown in Figure 2. According to the field test, the relevant process data are as follows.

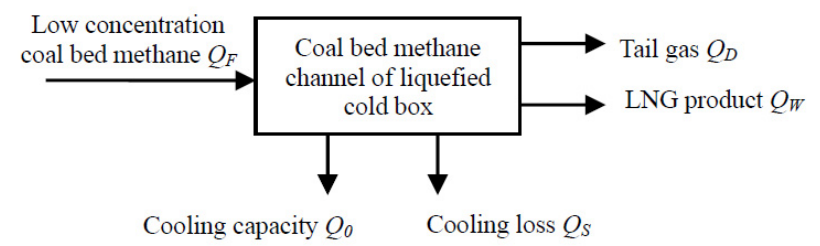

Figure 2. Energy balance diagram of coal bed methane channel in liquefied cold box

Before coal bed methane enters the plate fin heat exchanger, the pressure is $0.3 \mathrm{MPa}$ (gauge pressure, the same below), the temperature is $30{ }^{\circ} \mathrm{C}$, and the mole fraction of each component is as follows: $\mathrm{CH}_{4}$ is $35 \%$; $\mathrm{O}_{2}$ is $13 \% ; \mathrm{N}_{2}$ is $52 \%$. According to the above parameters, the specific enthalpy of feed gas entering the cold box is $1533.36 \mathrm{~kJ} / \mathrm{kmol}$.

The pressure of nitrogen and oxygen tail gas is $0.2 \mathrm{MPa}$, the temperature is $25{ }^{\circ} \mathrm{C}$, the mole fraction of each component is $0.8 \%$ for $\mathrm{CH}_{4}, 19.63 \%$ for $\mathrm{O}_{2}$ and $79.57 \%$ for $\mathrm{N}_{2}$. According to the above state parameters, the specific enthalpy is $105.1028 \mathrm{~kJ} / \mathrm{kmol}$.

The pressure of $\mathrm{LNG}$ product is $0.22 \mathrm{MPa}$, the temperature is $-152^{\circ} \mathrm{C}$, and the molar fraction of each component is as follows: $\mathrm{CH}_{4}$ is $99.5 \% ; \mathrm{O}_{2}$ is $0.5 \%$. Specific enthalpy $-10192.6956 \mathrm{~kJ} / \mathrm{k}$ mol.

According to the above data, the heat balance calculation of CBM channel is carried out according to the following correlation formula:

$$
Q_{F}+Q_{S}=Q_{0}+Q_{D}+Q_{W}
$$

Where, the heat of oxygen-containing coal bed methane $Q_{F}=1533.3615 \times \frac{12500}{22.4}=855670.5 \mathrm{~kJ} / \mathrm{h}$; the heat of oxygen-containing coal bed methane $Q_{D}=105.1028 \times \frac{8169}{22.4}=38329.7 \mathrm{~kJ} / \mathrm{h} ;$ Heat of nitrogen and oxygen tail gas $Q_{W}=-10192.6956 \times \frac{4331}{22.4}$
$=-1970739.5 \mathrm{~kJ} / \mathrm{h}$; Cooling capacity loss is $6.5 \mathrm{~kJ} /\left(\mathrm{m}^{3}\right.$ feed gas ), that is $Q_{S}=6.5 \times 12500=81250 \mathrm{~kJ} / \mathrm{h}$. Therefore, the cooling capacity required for the coal bed methane to cool to low temperature is $Q_{0}=2.87 \times 106$ $\mathrm{kJ} / \mathrm{h}=797.2 \mathrm{~kW}$.

\subsection{Distillation tower parameters}

Before CBM enters the distillation tower, the resistance in the plate-fin heat exchanger group is about $0.08 \mathrm{MPa}$, so the operation pressure of the distillation tower is $0.22 \mathrm{MPa}$. The state of CBM after precooling is as follows: the pressure is $0.22 \mathrm{MPa}$, the temperature is $-176^{\circ} \mathrm{C}$, and the mole fraction is as follows: $\mathrm{CH}_{4}$ is $35 \%, \mathrm{O}_{2}$ is $13 \%, \mathrm{~N}_{2}$ is $52 \%$; flow rate $=12500 \mathrm{~m}^{3} / \mathrm{h}$. Nitrogen and oxygen tail gas: $0.20 \mathrm{MPa}$, flow rate $=8169 \mathrm{~m}^{3} / \mathrm{h}$. LNG product: $0.23 \mathrm{MPa}$, methane molar fraction $99.5 \%$.

According to the above data, the numerical simulation of the distillation column is carried out, and the calculation results are as follows: theoretical plate number is 15 (including reboiler and condenser), feed position is the fifth plate, reflux ratio is 0.1905 , reboiler load is $429.58 \mathrm{~kW}$, condenser load is $-120.72 \mathrm{~kW}$.

\subsection{Refrigerant compressor parameters}

Refrigerant compressor is the heart of refrigeration cycle, which provides power for refrigeration of cold box, and also provides energy for consumption "big household" of the whole project. The selection of parameters directly relates to the reliability and economy of the operation of the device. In the liquefaction process of natural gas, if mixed refrigerant is used for refrigeration, the refrigerant is generally selected from $\mathrm{N}_{2}, \mathrm{CH}_{4}, \mathrm{C}_{2} \mathrm{H}_{4}$ or $\mathrm{C}_{2} \mathrm{H}_{6}, \mathrm{C}_{3} \mathrm{H}_{8}$, $\mathrm{C}_{4} \mathrm{H}_{10}, \mathrm{C}_{5} \mathrm{H}_{12}$ and other substances. The performance of $\mathrm{C}_{2} \mathrm{H}_{4}$ is slightly lower than $\mathrm{C}_{2} \mathrm{H}_{6}$, but the cost of $\mathrm{C}_{2} \mathrm{H}_{4}$ is much lower than $\mathrm{C}_{2} \mathrm{H}_{6}$. Considering the economic performance, $\mathrm{C}_{2} \mathrm{H}_{4}$ is selected for this device. According to the preliminary test and research, the mixture refrigerant is proposed to use the proportion shown in Table 2 with flow rate of $31250 \mathrm{~m}^{3} / \mathrm{h}$.

Table 2. Mole fraction of each component of refrigerant mixture

\begin{tabular}{|c|c|c|c|c|c|c|}
\hline material & $\mathrm{N}_{2}$ & $\mathrm{CH}_{4}$ & $\mathrm{C}_{2} \mathrm{H}_{4}$ & $\mathrm{C}_{3} \mathrm{H}_{8}$ & $\mathrm{C}_{4} \mathrm{H}_{10}$ & $\mathrm{C}_{5} \mathrm{H}_{12}$ \\
\hline mole fraction & 0.366 & 0.31 & 0.158 & 0.025 & 0.082 & 0.057 \\
\hline
\end{tabular}

Before the mixed refrigerant enters the compressor, the pressure is $0.08 \mathrm{MPa}$, the temperature is $25{ }^{\circ} \mathrm{C}$; the pressure after compression is $4.38 \mathrm{MPa}, 50{ }^{\circ} \mathrm{C}$. The ratio of absolute pressure before and after compression is 4.48 $\div 0.18=24.89$. In order to ensure safety and reduce the power consumption of the compressor, the three-stage compression and intermediate cooling are adopted, and the ratio of three-stage pressure is 2.92 . According to the relevant data, the adiabatic efficiency is $80 \%$.For the sake of insurance, the inlet water of cooling water is $0.2 \mathrm{MPa}$, $30^{\circ} \mathrm{C}$, and the outlet water is $50^{\circ} \mathrm{C}$. After calculation, the total power consumption of the compressor is $4284 \mathrm{KW}$, 
and the cooling water circulation capacity is $193 \mathrm{t} / \mathrm{h}$.

\subsection{Safety measures}

The low concentration CBM is inflammable and explosive. In order to operate safely, stably and continuously operation for a long period, corresponding safety measures are set up in three levels: safety system, process link and specific single equipment in the plant. The pressure vessel is equipped with safety valve and bursting disc. When the pressure of the vessel is greater than the rated unloading pressure of the safety valve, the safety valve opens and the drain main pipe is drained. In the case of safety valve failure, the bypass gate valve of the safety valve can be opened for pressure relief; the electrical equipment in the plant area is explosion-proof, the socket is equipped with leakage protection, and the electrical circuit is laid directly with armored cable; the whole equipment is explosion-proof, and the socket is equipped with leakage protection; the electrical circuit is directly buried with armored cable; The whole plant explosionproof electrical design, installation and selection of electrical equipment are carried out in accordance with relevant standards and specifications; DCS and ESD system are adopted to realize the distributed control of the plant and emergency stop of accident state. In terms of lightning protection, class I lightning protection is adopted and independent lightning receiving device is set. In the aspect of anti-static, copper skin jumper and automatic resistance detection are adopted to ensure that the grounding resistance of the device is less than $1 \Omega$.

An automatic explosion suppression device is installed in front of the feed gas compressor, including an automatic explosion suppression valve, an automatic powder spraying explosion suppression device, and a water seal fire-proof and explosion venting device. Detection elements of safety assurance system are installed at the inlet end of key equipment, such as flame sensor and pressure sensor. In order to increase the reliability, the system is equipped with a separate control device, which operates independently and is not controlled by the DCS control system in the plant area. In case of flame or overpressure at any detection point, the corresponding signal will be transmitted to the control device through the sensor, the explosion-proof valve will immediately cut off the gas source, and the automatic powder spraying device will immediately spray powder to prevent the flame from spreading; in case of overpressure, the safety valve, bursting disc and bursting disc of water seal fire-proof and explosion relief device in the plant are operated to ensure the safety of equipment and operators in the plant.

\section{Analysis of practice effect}

By adopting the CBM comprehensive utilization technology, the coal mine can basically realize the full utilization of the gas extracted (except for the maintenance period of the device), and the annual additional gas consumption is about 53.38 million $\mathrm{m}^{3}$, which is equivalent to 767,000 tons of $\mathrm{CO}_{2}$ equivalent emission reduction. In addition, after the completion and operation of the project, it is estimated that the annual average income is 211 million yuan, and the annual average net profit is 84.98 million yuan. The financial risk of the investment and construction is small, and the economic effect is obvious.

\section{Conclusion}

(1) The low concentration coal bed methane extracted from the coal mine is comprehensively utilized according to the energy demand of the mining area. The low concentration coal bed methane with concentration of about $5 \%$ is transformed into high-temperature flue gas by regenerative oxidation, and the heat energy is extracted to realize heat supply in the mining area; the unused and empty coal bed methane with concentration of more than $35 \%$ is purified and liquefied into LNG product by cryogenic liquefaction, so as to realize long-distance transportation. The comprehensive utilization scheme of low concentration coal bed methane in coal mine follows the principle of "zero discharge of gas drainage, comprehensive utilization of heat energy and maximum benefit", which can basically realize the full utilization of gas drainage.

(2) The comprehensive utilization technology of low concentration coal bed methane can not only improve the air environment quality of the project site, but also alleviate the contradiction between supply and demand of gas shortage in the mining area, and realize the sustainable development of the enterprise.

(3) Low concentration coal bed methane comprehensive utilization is an important resource comprehensive utilization technology, which integrates the functions of realizing the energy demand of coal mining enterprises, reducing cost and increasing efficiency, promoting mine safety production, improving gas utilization rate, optimizing energy structure, promoting energy conservation and emission reduction. The gas source of the coal mine is stable and reliable, all construction conditions are available, the adopted technology is safe and feasible, and the project has remarkable energy saving, environmental protection, social and economic benefits.

\section{Acknowledgements}

This work was supported by the China National Science and Technology Major Project (2016ZX05045-006) and the technology innovation and entrepreneurship fund special project of Tiandi Technology Co., Ltd. (2019-TDZD004). The authors gratefully acknowledge the support provided by Technical Institute of Physics and Chemistry, CAS for the experimental study.

\section{Funding}

This research was funded by the China National Science and Technology Major Project (2016ZX05045-006) and the technology innovation and entrepreneurship fund special project of Tiandi Technology Co., Ltd. (2019-TD- 
ZD004). The APC was funded by the technology innovation and entrepreneurship fund special project of Tiandi Technology Co., Ltd. (2019-TD-ZD004).

\section{References}

1. Zhou H. Air pollution control action plan [J]. Green China, 2017, No. 474 (08): 55-57.

2. Jiang S, Xue Z, Li W, et al. The environmental air quality and the impact of air pollution on health in China $[\mathrm{J}]$. North China electric power technology, 2015, 000 (008): 7-13.

3. Ma H, Wang L, Jia H, et al. Experimental Study on Desorption Characteristics of Coal bed methane under Variable Loading and Temperature in Deep and High Geothermal Mine [J]. Advances in Civil Engineering, 2020, 2020(3):1-17.

4. Richardson A D , Hollinger D Y, Shoemaker J K, et al. Six years of ecosystem-atmosphere greenhouse gas fluxes measured in a sub-boreal forest [J]. Scientific Data, 2019, 6(1):117.

5. Ngnikam E, Tanawa E, Rousseaux P, et al. Evaluation of the potentialities to reduce greenhouse gases (GHG) emissions resulting from various treatments of municipal solid wastes (MSW) in moist tropical climates: application to Yaounde [J]. Waste Management \& Research the Journal of the International Solid Wastes \& Public Cleansing Association Iswa, 2002, 20(6):501.

6. $\mathrm{Pu} \mathrm{H}$, Zhang L, Dong X, et al. Simulation of the Extraction Efficiency of Coal bed methane under Water Injection: A Gas-Liquid-Solid Coupling Model [J]. Geofluids, 2020, 2020(3):1-14.

7. Cheng Y P, Dong J, Li W, et al. Effect of negative pressure on coal bed methane extraction and application in the utilization of methane resource $[\mathrm{J}]$. Journal of China Coal Society, 2017, 42(6):14661474.

8. Cheng Y P, Dong J, Li W, et al. Effect of negative pressure on coal bed methane extraction and application in the utilization of methane resource [J]. Journal of China Coal Society, 2017, 42(6):14661474.

9. Kang J. Experimental study on wellbore heating technology of low concentration gas thermal storage oxidation [J]. Coal science and technology, 2018, 046 (006): 211-216.

10. Lian C. Research and practice effect of coal and gas $\mathrm{CO}$ mining and sharing technology in small high gas coal mine [J]. Mining research and development, 2019 (11): 63-66.

11. Yuan L, Xue J. Key technology of CO mining non pillar coal and gas in low permeability coal seam group [J]. Coal science and technology, 2013, 41 (1): 5-11.

12. Zhang $X$, Zhang Z, et al. Study on gas emission law and comprehensive treatment in Yangquan mining area [J]. Coal science and technology, 2014, 42 (9):
123-125.

13. Luo S. Design of low concentration gas thermal storage oxidation heating in Huoerxinhe coal mine [J]. Shaanxi coal, 2019, 038(004):10-13.

14. Huang K, Wang Y, Xiao Z. Application of ESD system in low concentration coal bed methane oxygen liquefaction device [J]. Mining safety and environmental protection, 2012, v.39; No.200 (001): 36-39. 